\title{
Government Guidance Strategies for the Development of Micro-enterprises
}

\author{
Chun-Liang Chen ${ }^{1, *}$, Chi-Ying Hung ${ }^{2}$, Shu-Hui Huang ${ }^{3}$, Ya-Juan Gao ${ }^{4}$ and Wen-Zhong Su ${ }^{5}$ \\ ${ }^{1}$ No. 59, Sec. 1, Daguan Road, Banciao District, New Taipei City, Taiwan University of Arts, Taiwan, R.O.C \\ ${ }^{2}$ Graduate School of Creative Industry Design, Taiwan University of Arts, Taiwan, R.O.C \\ ${ }^{3}$ Graduate School of Creative Industry Design, Taiwan University of Arts, Taiwan, R.O.C \\ ${ }^{4}$ Academy of Art and Design, Wuhan Technology and Business University, Wuhan City, China \\ ${ }^{5}$ Graduate School of Creative Industry Design, Taiwan University of Arts, Taiwan, R.O.C \\ ${ }^{*}$ Corresponding author
}

\begin{abstract}
The purpose of this study is to identify the different strategies employed by micro- enterprises supporting by the government funding with different developmental stage of industrial life cycles. This paper used a multiple-cases study method and selected 48 cases micro-enterprises to analyze the developmental phases of these firms.
\end{abstract}

Keywords-micro-enterprises; guidance strategy; industrial life cycles; developmental stage

\section{INTRODUCTION}

Micro-enterprises and entrepreneurs not only reinforce regional economies, but contribute to a country's economic development as well. In order to encourage the healthy growth of these small business, Taiwan's Small and Medium Enterprise Administration of Ministry of Economic Affairs (MOEA) launched the "Support and Guidance Program for Micro-enterprises and Entrepreneurs" in June 2012. The purpose of this program is to encourage these businesses to develop creativity, employ resources to produce value-added products and services, thereby increasing Taiwan's competitive edge in the global market. This program is a manifestation of the government's commitment to enhance the development of small firms by helping them share knowledge and creativity, building a corporate community, creating opportunities for cross-industry alliance, while developing a training mechanism for future managerial staff. Moreover, the program is also promoting a rating management system for these smaller firms, in hopes that through franchising and innovative incubation, startups will be able to innovate and secure a place in the intensely competitive market.

Through this program, the government can utilise related policy tools to motivate private sectors in conducting research for improving economic growth and accumulating national wealth. However, despite the technology development projects that have been introduced worldwide, stakeholders have debated the effectiveness of such projects. Accordingly, project supporters bring up success stories to support the viability and necessity of a project proposal, whereas project opponents recount "horror" stories to elucidate the wastage and shortcomings of such proposals [1]. Therefore, the assumptions of this study precipitated investigating such stories and analysing the tools and implications of firm participating Government Development Program (GDP). This study explores the small enterprise tools provided by the Taiwanese government. We also examine the circumstances facing small enterprises through the lens of industrial life cycles. As [2] suggested, firms must plan the path toward value innovation according to the life cycle conditions of their industry.

In summary, the purpose of this study is to identify the different strategies employed by micro-enterprises supporting by the government funding with differing developmental stage of industrial life cycles.

\section{LITERATURE REVIEW}

\section{A. Industrial Life Cycle}

Different industries operate under different market circumstances, and therefore require divergent strategies to cope with the situation at hand. Reference [3] stated that industrial life cycles contain four distinct stages: introduction, growth, maturity, and decline. Reference [4] also suggested that in terms of its growth speed and market saturation, an industry's development is divided into four phases: introduction, growth, maturity, and decline. Distinct problems arise with each phase, and they each require independent solutions.

\section{B. The Market Development Life Cycle}

Reference [5] stressed that it is common for obstacles to arise when a firm attempts to navigate the innovation process. He posited that a firm must employ different types of innovation that correspond to the distinct phases of market development. Only if the firm chooses the right type of innovation can it gain competitive advantage through differentiation. Thus Moore developed the theory of the market development life cycle, asserting that the technology industry provides the most satisfactory materials for exploration into market development. A firm's chances of success improve remarkably by choosing the most appropriate strategy at each distinct phase of market development [6],[7].

In this study, we divide the developmental stages of the micro-enterprise according to the industrial life cycle and market development. 


\section{MethodOLOGY}

The case study method involves using single or multiple cases to focus on social phenomena. Additionally, a substantial quantity of diverse and detailed data can be acquired from relatively few target cases [8]. A case study can be used to thoroughly explore the patterns or behaviours of individuals, groups, or institutions and the relationships, or between the associated factors of these subjects. Moreover, this type of study involves diverse data collection and comparison analyses for verifying the connotative traits or patterns of the research subjects. Additionally, a logical thought process can be used to identify methods for resolving associated problems. Reference [9] asserted that case studies, which emphasise background contexts, can be used to demonstrate actual decision-making scenarios. In a case study, researchers can closely interact with target actors and investigate the actual process in which decisions are made to solve managerial problems. Consequently, a case study can be used to provide practical management knowledge [10]. This paper used a multiple-case study method to exploring and understanding the conditions and practical phenomena of the case subjects under actual situations. Additionally, multiple methods of data collection can be used to acquire information regarding an individual or several subjects (people, groups, or organizations) [11],[12]. The purpose of this paper is to identify how the micro-firms needed the Government Development Program resources in their growth stages, hence, the multiple-case study method is applicable to examining such study topic [12].

This study selected 48 cases from the Government Microenterprises and Self-employed Businesses Support and Guidance Program in Taiwan. We analyzed the developmental phases of these firms and reached conclusions about the guidance provided to them by the government. According to the principle of data triangulation, this study applied evidence from multiple sources and constructed a database for conducting the multiple-case study [12],[10]. The secondary data, interview contents, and related word documents were used to establish the database that served as the basis for conducting subsequent analyses. Additionally, the following three procedures were applied to compile and analyse the collected data [12]: (a) The statements of each case firm were organised to indicate major findings. (b) Each case firm was analysed to identity its uniqueness. (c) A cross-case analysis was conducted to compile the data of the case firms, conclude our findings, and propose recommendations for associated organisations.

\section{CASE ANALYSIS}

This study compiled the guidance types supplied by the government to assist the 48 micro-enterprises as shown in Table 1:

This study divided the 48 cases into three categories: "Initial phase" (0-3 years), "Innovative development phase" (3-5 years) and "Transition and upgrade phase" (over 5 years), and split the micro-enterprises into "innovative type" and "traditional type" in accordance with their operational style. Figure 1 shows the correlation between the guidance measures taken by the government and the small businesses that received aid at different stages of development. Most small businesses tend to need guidance in the following respects: product packaging, design and promotion; introduction of external resources; community integration for added value; distribution of new products/services; and purpose-oriented marketing. The guidance strategies and corresponding phases of corporate development are as follows:

\section{TABLE I. THE GUIDANCE TYPES AND MEASURES TAKEN BY THE GOVERNMENT TO ASSIST THE MICRO-ENTERPRISES}

\begin{tabular}{|l|l|}
\hline \multicolumn{1}{|c|}{ Guidance strategies } & \multicolumn{1}{|c|}{ Measures } \\
\hline $\begin{array}{l}\text { Product packaging, } \\
\text { design and promotion }\end{array}$ & $\begin{array}{l}\text { Optimization of product design, packaging, and } \\
\text { service as well as advertising promotions. }\end{array}$ \\
\hline $\begin{array}{l}\text { Introduction of } \\
\text { external resources }\end{array}$ & $\begin{array}{l}\text { Built connections between external resources } \\
\text { such as capital and technology and } \\
\text { micro-enterprises and the self-employed. }\end{array}$ \\
\hline $\begin{array}{l}\text { Community Integration } \\
\text { By recruiting cooperative partners the program } \\
\text { attempted to enhance operational efficacy and } \\
\text { promotion of micro-enterprises and } \\
\text { entrepreneurs. This differs from the } \\
\text { "Distribution of New Product/Service" guidance } \\
\text { model because it stresses operational or } \\
\text { technological capabilities for the firm via } \\
\text { cross-industry cooperation. }\end{array}$ \\
\hline Distribution of new \\
products/services
\end{tabular}

1) Product packaging, design and promotion: This strategy is applicable for traditional micro-enterprises at the initial stage or the transition and upgrade phase, and can help secure their operational capabilities while easing transitional difficulties.

2) Commercial community operation: This strategy is applicable for all traditional micro-enterprises and entrepreneurs at all phases. Since traditional firms are liable to face operational obstacles both in commodity and service promotion, it is vital for such firms to create new business opportunities by combining virtual information and sales channels.

3) Objective-oriented marketing: This strategy applies to all types of firms at all stages. Micro-enterprises and entrepreneurs tend to lack marketing channels for advertisement and promotion. Unlike big companies, these small firms often benefit from awards, trade fairs, or building a visible local brand, and need not to spend large sums of money on marketing. 
4) New products/services delivery: This strategy suits the "innovative type" of miniature firms regardless of what stage they are in. By providing innovative operations for the distribution of products and services, this model prioritizes the combination of innovative commodities in a cross-industry fashion in order to create a win-win situation.

5) Introduction of external resources: This strategy suits innovative micro-enterprises and self-owned businesses at both the initial and transition and upgrade phases. A firm has a strong need for technology in the initial stage, as it is developing new products and operational capability. The introduction of external resources is vital as the firm secures a place in the market. However, venture capital investments or angel investors are in the most urgent demand when a company is at the transition and upgrade stage.

\begin{tabular}{|c|c|c|c|c|}
\hline \multirow[t]{4}{*}{ innovative type } & $\begin{array}{c}\text { Introduction } \\
\text { of external } \\
\text { resources }\end{array}$ & & $\begin{array}{c}\text { Introduction } \\
\text { of external } \\
\text { resources }\end{array}$ & \\
\hline & \multicolumn{4}{|c|}{ New products/services delivery } \\
\hline & \multicolumn{4}{|c|}{ Objective-oriented marketing } \\
\hline & \multicolumn{3}{|c|}{ Commercial community operation } & \\
\hline \multirow[t]{2}{*}{ traditional type } & $\begin{array}{l}\text { Product } \\
\text { packaging, } \\
\text { design and } \\
\text { promotion }\end{array}$ & & $\begin{array}{l}\text { Product } \\
\text { packaging, } \\
\text { design and } \\
\text { promotion }\end{array}$ & \\
\hline & Initial phase & $\begin{array}{c}\text { Innovative } \\
\text { development } \\
\text { phase }\end{array}$ & $\begin{array}{c}\text { Transition and } \\
\text { upgrade } \\
\text { phase }\end{array}$ & $\begin{array}{l}\text { Small Businesses } \\
\text { Development Stages }\end{array}$ \\
\hline
\end{tabular}

FIGURE I. THE CORRELATION BETWEEN THE GUIDANCE MEASURES TAKEN BY THE GOVERNMENT, AND SMALL BUSINESSES AT DIFFERENT STAGES OF DEVELOPMENT

\section{CONCLUSION AND SUGgESTIONS}

This study analyzed 48 micro-enterprises by dividing them into different developmental stages; besides, comparing the innovative types and traditional types in the development process. Through the discovery of different similarities and dissimilarities in the industrial development process, the research aims to giving introspections and reflections to further management implications. The study focuses on the discussion of micro-enterprises through data analysis and usage of governmental resources. It appears that most miniature firms need guidance in the following respects: product packaging, design and promotion; introduction of external resources; community integration for added value; distribution of new products/services; and purpose-oriented marketing. Small businesses have different guidance needs at each stage of the life cycle. Therefore, it is vital for the government to take action and invest in resources that contribute to the development of these small firms. This can best be done if the types of enterprises are taken into consideration, and split into "innovative types" and "traditional types." Our cases evidence suggests that innovative-type small firms are better at elite-style development, whereas traditional-type firms are more prone to industrial clusters.

This study advises the government to formulate different strategies for micro-enterprises depending on their operational styles and developmental phases. Resources can then be more efficiently allocated to facilitate the firms' development.

\section{ACKNOWLEDGMENT}

The authors would like to acknowledge research funding and support from the Ministry of Science and Technology Ministry of Science and Technology, Taiwan, R.O.C. under grant MOST 104-2420-H-144-001.

\section{REFERENCES}

[1] Wallsten, S. J., "The effects of government-industry R\&D programs on private R\&D: the case of the Small Business Innovation Research program. ” RAND Journal of Economics, vol.31(1), pp. 82-100, 2000.

[2] Chen, Jie-Rong, The Case Study on relationship between market development life cycle and value innovation approach, Taiwan, 2008。

[3] Porter, M.E., “Competitive Strategy: Techniques for Analyzing Industries and Competitors.”, New York: Free Press, 1980.

[4] Wu, Se-Hwa;Hung, Chien-Min, "Comparative Research on the Environmental Beliefs and Values of Business Managers,” Proceedings of the Second International Conference on Comparartive Management, 1989.

[5] Moore, Geoffrey A., "Darwin and the Demon: innovating within established enterprises”, Harvard Business Review, vol. 82(7), pp.86-92, 2004.

[6] Philip Kotler, A Framework for Marketing Management, Fifth Edition, 2003.

[7] Philip Kotler, Marketing Management: An Asian Perspective, 6/E, 2007.

[8] Patton, M. Q., How to use qualitative methods in evaluation. Newbury Park, CA: Sage, 1987.

[9] Eisenhardt, K. M., \& Graebner, M. E., "Theory building from cases: Opportunities and challenges. Academy of Management journal, " vol.50(1), pp. 25-32, 2007.

[10] Gibbert, M., Ruigrok, W., \& Wicki, B., "What passes as a rigorous case study? Strategic Management Journal, ” vol.29(13): pp. 1465-1474, 2008.

[11] Benbasat., "The case research strategy in studies of information systems, ” MIS Quarterly, vol. 11(3), pp. 369-388, 1987.

[12] Yin, R. K., Case study research: Design and methods. Thousand Oaks, CA: Sage, 2003. 